\title{
Tagging Time in Prolog: The Temporality Effect Project
}

\author{
Jan Christoph Meister \\ University of Hamburg, Germany
}

\section{Abstract}

This article combines a brief introduction into a particular philosophical theory of 'time' with a demonstration of how this theory has been implemented in a Literary Studies oriented Humanities Computing project. The aim of the project was to create a model of text-based time cognition and design customized markup and text analysis tools that help to understand "how time works": more precisely, how narratively organised and communicated information motivates readers to generate the mental image of a chronologically organized world. The approach presented is based on the unitary model of time originally proposed by McTaggart, who distinguished between two perspectives onto time, the so-called A- and B-series. The first step towards a functional Humanities Computing implementation of this theoretical approach was the development of TempusMarker-a software tool providing automatic and semi-automatic markup routines for the tagging of temporal expressions in natural language texts. In the second step we discuss the principals underlying TempusParser-an analytical tool that can re-construct temporal order in events by way of an algorithm-driven process of analysis and recombination of textual segments during which the 'time stamp' of each segment as indicated by the temporal tags is interpreted.

Correspondence:

Dr. Jan Christoph Meister, Narratology Research Group, c/o Institut für Germanistik II, Universität Hamburg,

Von-Melle-Park 6,

D-20146 Hamburg,

Germany

E-mail:

jan-c-meister@uni-hamburg.de
For many of us the fictional worlds, which we encounter via media of narrative representation-worlds depicted in novels, novellas, fairy tales, movies, dramas, operas etc.- - regularly match and often even surpass reality in terms of their emotional effect. Paradoxically as it may seem we must be willing to suspend the very ontologic constraint that defines reality in order to experience this super-realistic pleasure of immersion: we have to accept that the things and events occurring in a fictional world need not necessarily exist in any empirical sense. Accordingly, we have become accustomed to assuming that the persons and objects that populate these worlds will probably have no reality outside the narrative, and we are aware that their spatial and historical dimensions are by default imaginary. In other words, we know that 
what is depicted in a fictional narrative is likely to have been made up. Yet this does not matter in the least bit: by aesthetic convention fictional worlds can be referentially void for as long as they are meaningful and relevant and allow us to relate our own life experiences to what goes on inside them. After all, the fictional world is presented to us as a probable alternative and not as a replica of the empirical world in which we ourselves exist; in short, it is a virtual, a possible world. ${ }^{1}$

Yet there is one particular aspect of empirical reality, which even these possible worlds will never be exempt from: time. One can refer to fictional space, persons, objects and events in a purely abstract manner and conceive them as mere possibilities, or as logic, semiotic or functional variables. ${ }^{2}$ But the experience of time will retain its phenomenological reality even in a fictional context, if nothing else because of the fact that our cognitive processing of imagined objects and events nevertheless takes real time. Conversely, it is almost impossible to conceive of time independent from experience, a philosophical problem discussed already by Augustine toward the end of the 4th century in his autobiographic Confessiones. After contemplating the timeless existence of God, Augustine exclaimed:

For what is time? Who can easily and briefly explain it? Who can even comprehend it in thought or put the answer into words? Yet is it not true that in conversation we refer to nothing more familiarly or knowingly than time? And surely we understand it when we speak of it; we understand it also when we hear another speak of it.-What, then, is time? If no one asks me, I know what it is. If I wish to explain it to him who asks me, I do not know. Yet I say with confidence that I know that if nothing passed away, there would be no past time; and if nothing were still coming, there would be no future time; and if there were nothing at all, there would be no present time.-But, then, how is it that there are the two times, past and future, when even the past is now no longer and the future is now not yet? But if the present were always present, and did not pass into past time, it obviously would not be time but eternity. If, then, time present-if it be time-comes into existence only because it passes into time past, how can we say that even this is, since the cause of its being is that it will cease to be? Thus, can we not truly say that time is only as it tends toward nonbeing?

Augustine (1955): Book XI, Chapter 14

Note that Augustine referred to the philosophical conundrum of real world time experience, that is, to the cognitive phenomenon of things coming and passing away, which on the one hand seems to testify to time's existence, while on the other hand splitting up time into three separate ontological domains (future, present, past). These deliberations of course focused as much on the epistemological as on the spiritual aspect of time perception. ${ }^{3}$ Gaining insight into how time
1 On narrative representations as 'possible worlds' see Ryan (1991).

2 See for example the Formalist notion of 'function' introduced by Propp (1984), which was meant to replace the naïve mimetic concept of 'character'. This functionalist approach of course goes way back to Aristotle's Poetics.

3 Ricoeur (1984) commences his study on the interrelation of time and narrative with a comprehensive interpretation of the quoted passage. For a detailed critique of Ricoeur's approach see Protevi (1999). 
perception in narratives work will surely not help us to solve Augustine's metaphysical problem of defining and understanding time as such. But apart from this evident difference in scope and profoundness there is also a methodological distinction to be kept in mind. Unlike Augustine, but also unlike modern natural sciences contemporary literary studies generally focus on the represented rather than on the empirical, a methodological orientation that in fact has a bearing on most humanities disciplines' conceptualizations of time. ${ }^{4}$ In this perspective time occurs as a by-product, a function or a constituent of cognitive processes rather than as their perceptual object. By contrast, the natural sciences (unless they consciously decide to transcend the Newtonian paradigm for the sake of refining increasingly abstract theoretical models of the physical world), and even more so the applied sciences, usually accept as an unproblematic given the objective existence of time as a metre for assessing the fourth, i.e. the temporal dimension of natural processes and occurrences. The problem that one cannot 'see' time as such, that it is inference based and not directly empirical of course remains, but the case is not really different from that of, say, magnetism or gravity which, too, only become apparent by their effects, but are nevertheless deemed to be objective facts or forces. Both are generally conceptualized as an attraction between objects located in space. Significantly, our favourite metaphor for expressing the notion of objective time is also based on a spatial analogy, namely that of the time-line or time-arrow. ${ }^{5}$

However, the assumed objectivity of time is immediately called into question once one takes the perceiving consciousness into the equation, and the problem of how to conceptualize time gets even more complex when we deal with a consciousness processing symbolic rather than sensory data. Yet the striking fact remains that even represented timethat is, time cognition as it is evoked in our minds by representational means, and among these first and foremost by narratives-feels perfectly real. We read a story and in that story certain events unfold sequentially. Clearly, there seems to be some temporal order in this sequence, and hence we will conclude that time does exist in the world depicted in this particular representation. How exactly does this illusion come about?

This question is at the core of the ongoing research project, which this article will present. ${ }^{6}$ Our aim is to develop a new model of narrative time, or more precisely: a model that will enable us to describe how and on the basis of which textual cues readers of narrative texts build the complex mental image of a temporally structured world. We have termed the outcome of this readerly activity the temporality effect, thereby alluding to Barthes' (1989) famous notion of the so-called reality effect. However, our narratological project equally falls into the domain of humanities computing in that the methodology of textual mark-up, data modelling, combinatorial data analysis and computer-aided visualization of time constructs play a crucial role in it. From this perspective our project's basic methodological assumptions 
prove to be similar to those in Drucker and Nowvieskie's (2003) temporal modelling project, and one of its components (the so-called 'B-algorithm'; see below) bears strong resemblance to Burg et al. (2000) constraint logic programming approach toward chronological analysis of narratives. However, what sets our model apart from these approaches is its foundation in a particular philosophy of time, which integrates non-temporal (sequential and logic) as well temporal principles of ordering in phenomena, be they empirical or represented. This unique combined perspective holds three important advantages. One, it allows for the joint modelling of subjective time experience and objective time structures. Two, because this philosophical approach traces the experience of time back to the processing of purely sequentially ordered information, it provides a strong conceptual basis for a computational analysis of the temporality effect, which focuses on the material of which narratives consists of in the most literal sense: mere strings of words, which are inherently devoid of any temporal quality. And thirdly, seen in combination these two characteristics of our project's philosophical foundation open up the possibility of a dynamic $3 \mathrm{D}$ visualisation of time experience.

\section{Narratological and Philosophical Tenets of the Temporality Effect Model}

Since the mid-1950s a number of well-established narrative theories and narratological taxonomies have dealt in detail with time and temporal ordering in narrative texts. Among the more recent and influential are Ricoeur's (1984-88) philosophically orientated Time and Narrative and the narratological contributions by Genette (1980, 1988), notably his books Narrative Discourse and Narrative Discourse Revisited. In these studies Genette outlines, among others, a welldefined taxonomy for describing phenomena of temporal ordering in narratives across the levels of story, plot and discourse. This taxonomy is arguably the most widely used in contemporary narrative studies.

However, an aspect disregarded in Genette's as in many other narrative or narratological theories of representational time constructs is that long before an ordered narratorial discourse takes shape, texts are by default already assumed to be located 'in time' by their readers simply because they are texts. A text as understood in the narrower sense of the word is a symbolic representation made up of an ordered string of characters. This characteristic of linear order in the arrangement of representational material is subconsciously conflated with the temporal linearity governing the processes by which that material is produced (written) or received (read), and the empirical temporality of these processes is then furthermore projected onto the representational content itself. The outcome of this naive, pre-critical mode of processing narratives is easy to predict-and almost impossible to avoid. The unconscious mapping of objective temporal order in cognitive processing onto logical order in the symbolic material, 
7 Iconic temporality is also the conceptual point of reference in Müller's (1948) influential distinction among Erzählzeit (time or duration of narration) and erzählte Zeit (the narrated time; the fictional amount of time taken up by the narrated events). According to Müller, Erzählzeit can be measured in terms of the quantity of representational material, i.e. the number of words and pages, which the reader has to process in order to build up the mental image of a fictional world. This number can then be related to the time, which the narrated events are reported to have taken within the narrated world. 'Fast' and 'slow' modes of narration can thus be distinguished by comparing their respective ratios of Erzählzeit to erzählte Zeit.

8 See Pöppel (1978). Pöppel tested the ability of humans to differentiate sensual phenomena; the so-called fusion threshold for acoustic phenomena stands at $1-2 \mathrm{~ms}$ and constitutes the finest level of granularity that we are capable of handling. The human ability to identify the way in which these individual phenomena are actually ordered is far less pronounced; here the phenomena have to be at least some $20 \mathrm{~ms}$ apart from each other before any of our senses will be able to identify their ordering principle (the so-called ordering threshold).On the 3 second extension of the 'window of cognition' that organizes human processing of texts see Wittmann and Pöppel (1999).

9 This default can of course be overridden by words or and from there onto its symbolic content is known to text linguists as the phenomenon of iconic temporality (see Lehmann, 1992; Lehmann and Rauchenecker, 1995). ${ }^{7}$ It is probably a cultural rather than an anthropological default that is most apparent in text-centred Western cultures, a default by which we have come to assume that what has been represented first in terms of the numerical order of characters or words, and was thus encountered first in the chronological order of our reading, did in fact happen in that order and took place within a world that is structured in a temporal sense. Non-linear principles of ordering-flashforwards, flashbacks, omissions etc. for which Genette has re-coined rhetoric terms, such as analepsis, prolepsis, elipsis-are hence described as second-order discursive techniques that result in a digression from what one assumes to be the 'natural' or isochronic representational order of a 1:1 relation among temporal order of events, and sequential order in the representational material. The model, which we are developing tries to take this iconographic dimension seriously, and our starting point, therefore, is to reduce the concept of narrative text to a dimension where it is not yet affected by temporality. This dimension is that of the numerically ordered sequence of words (and eventually, that of the mental images invoked by a certain class of them), which we use as a reference axis in our approach.

A second important philosophical tenet of our model is derived from Augustine and Husserl. Augustine's unique contribution to philosophy of time is the concept of the coexistent 'threefold present' (presence of the past, presence of the present, presence of the future) in the human mind. This idea reappears in Husserl's concept of the so-called 'Zeithof der Gegenwart', best translated as the 'time-window of the now', or in short, the now-window (Husserl 1966). According to Husserl human consciousness is by necessity located within such a subjective now-window, which knows no internal temporal differentiation, but from within which we anticipate the future by way of what Husserl calls 'Protention' (future-orientated imagination) and 'Retention' (past-orientated remembering; Husserl, 1985:34f. Both concepts are based on Augustinian ideas, notably that of the distensio animi as discussed in Ricoeur, $1984 \mathrm{ff}$ ). Husserl's speculative idea of the now-window has been supported by cognitive psychology and neurobiological studies of human reading habits, which suggest that in processing narrative texts, the average extension of a cognitive nowwindow is about $3 \mathrm{~s}$, regardless of the fact that our sense of hearing can actually individuate phenomena down to an astonishing $2 \mathrm{~ms}^{8}$ In practical terms this means that when we read a text, whatever falls within a $3 \mathrm{~s}$ window of perception is by default experienced as happening 'now', thereby constituting the impression of a present.' Whatever falls outside the boundaries of this window belongs to either the future or the past. Of course, the now-window, although measurable in its extensions, has no objective existence; it is just the subjective manifestation of what James (1950) aptly termed the 'specious present'. 
In 20th century philosophy of time the approach that best combines the three aspects of basic non-temporal numerical order, assumed objective temporal linearity in the world, and subjective experience of time as spreading out from a 'now'-position is that of McTaggart (1908). McTaggart proposed three concurrent ordering principles in events. These principles are, in descending order,

(1) the C-line; that is, events in their objective non- or pretemporal numerical or logical order;

(2) the B-line; that is, events 'stringed' in a continuous and absolute sequence of empirical before/after-relations; and

(3) the A-line; that is, events in their subjectively experienced dynamic relation toward an assumed 'now' from whose perspective they are seen to pass through a continuum of three temporal domains, namely past-present-future. ${ }^{10}$

\section{A-, B- and C-line Ordering in Practice: the Role of the Temporal Operators}

Our model combines the three McTaggart-lines with Husserl's idea of the now-window in order to define, in qualitative as well as in quantitative terms, the empirical textual features that trigger the temporality effect, that is, the reader's experience of temporality as an ordering principle at play in the represented world. We call these textual features temporal operators. Our premise is that the only empirical phenomenon, which we encounter in our processing of narratives actually is the string of words that a given narrative consists of. Certain subclasses of words (mainly nouns, pronouns and verbs) stimulate us to create mental images of either entities (objects, persons) or of events that populate the world, which we are reading about. It is important to note that the ordering principle governing the arrangement of the words that form the actual material substrate of imagined fictional entities is per se non- or pre-chronological: words read and processed by our brain merely occur in an ordered sequential progression. ${ }^{11}$ This means that prior to chrono-semantic processing by a reader the string of words that make up a narrative text, as well as the mental images of objects and events contained in that world, are ordered only in terms of McTaggart's C-line.

There are two ways by which these C-line ordered phenomena may subsequently become 'chrono-logized', so to speak. In narrative texts both depend largely (but not exclusively) on temporal operators, that is, on literal expressions or grammatical and formal features that can either contain content information on how events and entities occurring in the represented world are related to each other in terms of temporal succession (that is, in terms of the B-line principle of fictional objective time), or they can contain procession instructions telling us what element of the world to imagine when (articulating the A-line principle of subjective discourse time). The idea of temporal operators is best demonstrated by an example. Let us therefore look at syntactic features that carry temporal information, most importantly by temporal deictic and/or grammatical tenses.

10 The thrust of McTaggart's approach is to prove the two self-evident concepts of the A- and the B-line mutually exclusive by way of the so-called 'B-reduction thesis', which transforms A- into B-lines. This paradox is then used to argue for the metaphysical non-existence of time as such. The argument is of course philosophically intriguing and has lead to McTaggart's continued popularity in philosophy of time, triggering refutation after refutation. See for example Beer (1988) and Robinson (1987).

11 Since we are not concerned with function words and verbs but merely with expressions that represent entities and objectified events we will ignore the grammatical, syntactic and aesthetic ordering principles, which of course also organize a narrative text. 
the opening paragraph of Edgar Allen Poe's 1841 A Descent into the Maelstrom:

We had now reached the summit of the loftiest crag.

For some minutes the old man seemed too much exhausted to speak. 'Not long ago,' said he at length, 'and I could have guided you on this route as well as the youngest of my sons; but, about three years past, there happened to me an event as never happened before to mortal man-or at least such as no man ever survived to tell of - and the six hours of deadly terror which I then endured have broken me up body and soul. You suppose me a very old man-but I am not. It took less than a single day to change these hairs from jetty black to white, to weaken my limbs, and to unstring my nerves, so that I tremble at the least exertion, and am frightened at a shadow. $</ \mathrm{p}>$

As in any other case the C-line is originally manifested as a string of characters ranging from the first to the last ' $w$ '. Once we begin our reading and interpret typographic or lexematic units as semantic units we will identify the C-line at the level of numerically ordered mental images. We begin to imagine a sequence of entities populating this world-entities like 'we', 'summit', 'crag' etc. whose lexical representations (nouns and pronouns) one can parse fairly reliably, ignoring for the time being the recall problem inherent in any parsing technique. This C-line as such proves to be inalterable; it can neither be transformed nor modified. In other words-there are no C-operators other than paratextual ones.

As is typical for opening paragraphs in narratives our example text is extremely rich in temporal information. Running along the string of characters we come across numerous expression that inform us, either in absolute terms, such as 'minutes', 'years' or 'hours', or by way of deictic reference to the current temporal position of the hearer or speaker-'now', 'ago', 'at length', 'youngest', 'past', 'never' and so forth-about the position or duration of events along an imagined B-line, that is, the traditional time-line allowing us to understand which thing occurs before, during or after another. Preciseness and granularity in these expression-which we have termed B-operators and marked in bold script-vary considerably. However, they all serve the same purpose of informing us about what comes before, what is coexistent, and what comes after. In Poe's narrative reaching the summit occurs before witnessing the old man's exhaustion, and in turn the event that lead to the man's sudden ageing happened 3 years before we reach the summit, and so forth.

A-operators (underlined in the above quote) on the other hand are typically manifested in the form of a change in grammatical tense or mode, or as the beginning of a new paragraph, section or chapter. Whenever this occurs we are called upon to reposition our subjective now-window and rearrange our mental images of the past, present and 
Progression of the NOW-window of perception

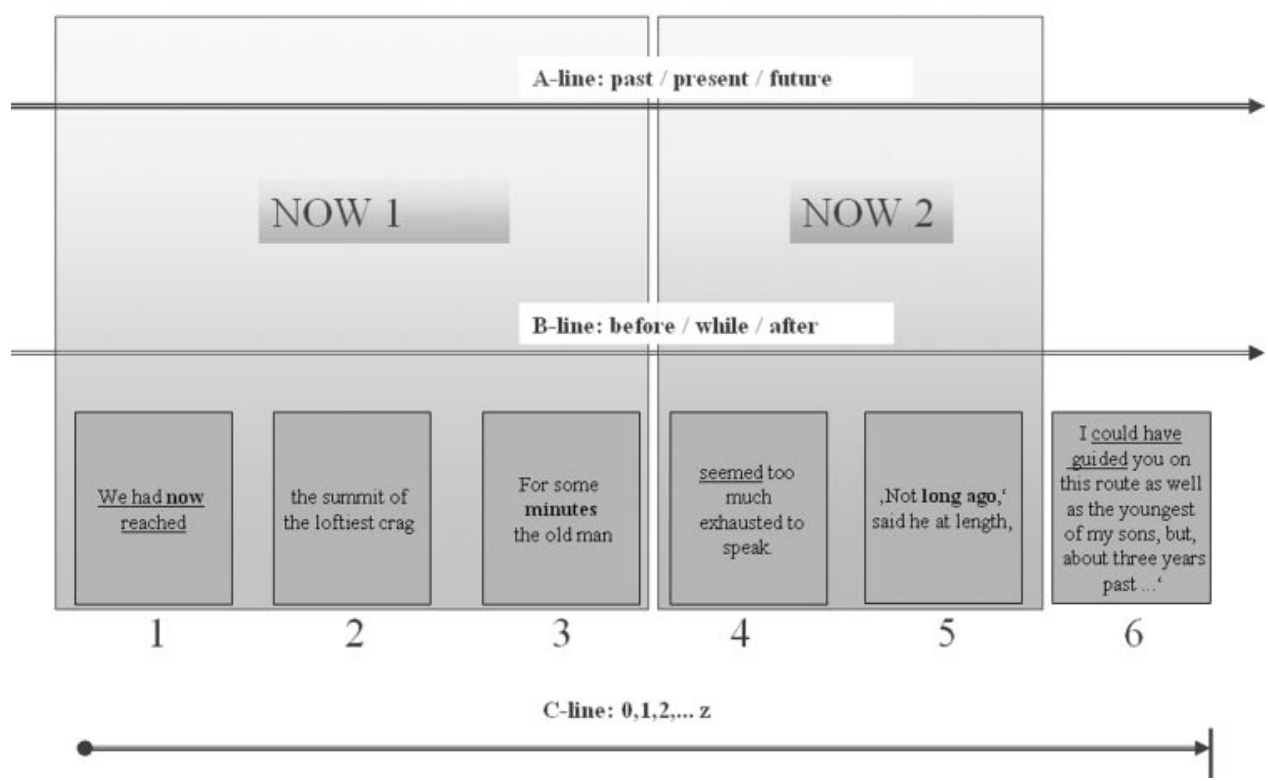

Fig. 1 First two instances of the now-window and B-line ordering of successive mental images

future of the represented world. As we see the first now-window in our example is literally denoted by tying the first B-operator-namely the indexical 'now' in the third word-to the past perfect ('had reached'). The next A-operator occurs with the switch to the past tense ('seemed'), and so forth until we eventually reach a particularly powerful A-operator in the form of the paragraph mark, which concludes the fifth sentence. Each of these A-operators serves as a processing instruction to relocate our now-window. Figure 1 gives a schematic representation of the first two instances of the now-window, which we construct as our reading progresses along the C-line. Here the boundary between now-windows 1 and 2 is demarcated by an A-operator switch from past perfect to past tense.

However, once we reach the sixth text block we will encounter the pairing of a temporal flashback (analepsis) indicated on the B-line by the B-operator expression 'but, about 3 years past' with an A-operator (the switch to the subjunctive and perfect tense). The effect on the construction and positioning of the next instance of the now-window is considerable, as Figure 2 demonstrates.

\section{Computational implementation of the Model}

In terms of our theory the temporality effect is essentially a function of this interplay of B- and A-line computations in the reader's mind, which take place against the background of the static C-line as a frame 
McTaggart's $\mathrm{A} / \mathrm{B} / \mathrm{C}$-line and the NOW-window of perception

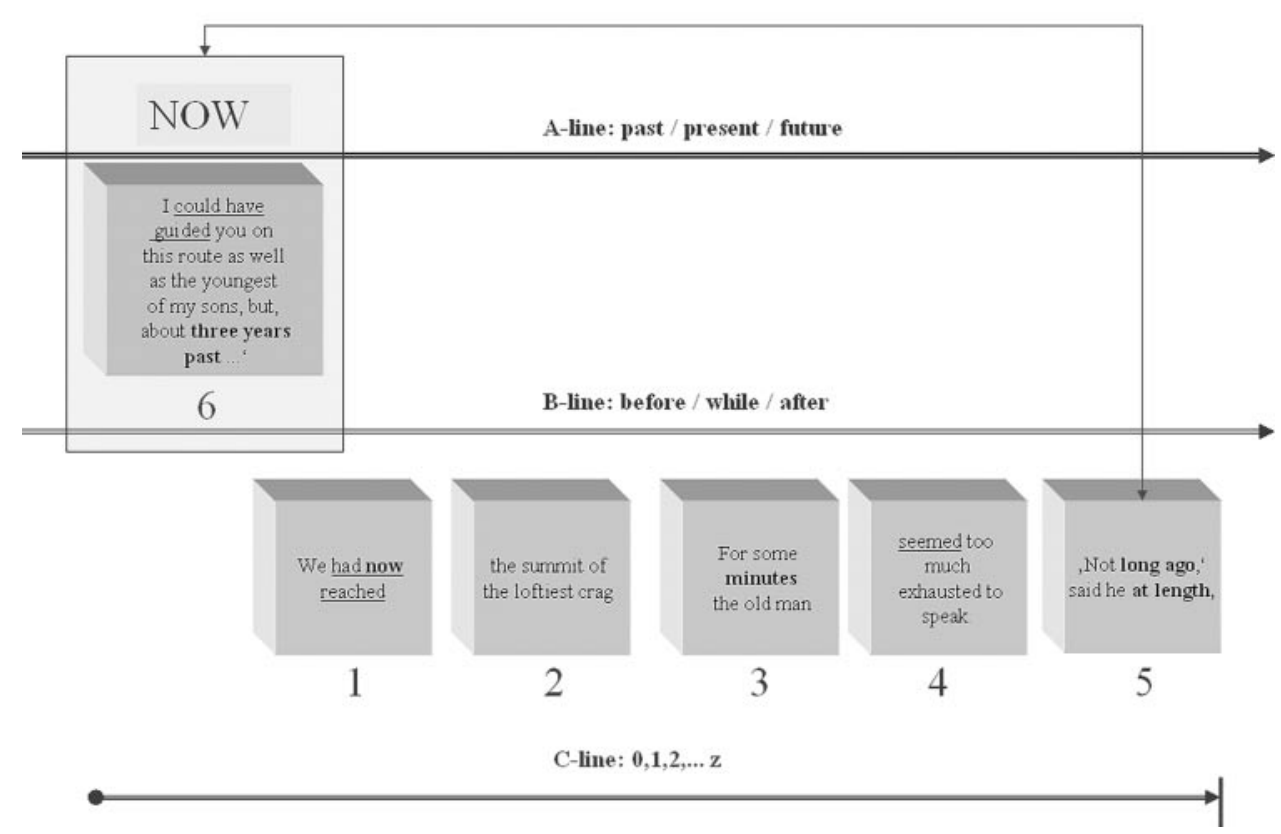

Fig. 2 Repositioning of the now-window effected by A-operator in text block 6

of reference, which is processed ('read') sequentially. Implementation of this theory in a model that is based on computational methodology requires us to resolve three issues:

(1) Define a mark-up convention and design a mark-up tool that will enable us to tag the empirical lexical and typographical elements serving as A- and B-operators within an extended string of characters-i.e., within a 'text'.

(2) Define and program two sorting algorithms that can process the tags, one for handling dynamic B-line computations, a second one for computing the positions for the changing A-line anchoring and extension of the 'now-windows'. Both these computations take place in relation to the variable C-line delimitation of the quantity of text string processed.

(3) Identify a visual metaphor, which can adequately represent the dynamic as well as the multi-dimensional characteristic of temporal constructs as conceptualized in the temporality effect-model.

\subsection{Mark-up convention and tool}

Initially our intent was to tag A- and B-operators using standard TEI-tags (Sperberg-McQueen and Burnard 2002). However, we soon found that neither the TEI core tag set nor the additional tag sets enable us to capture the difference between A- and B-operators: the process 
orientated notion of 'temporal operator' itself is hard to reconcile with that of 'temporal expression', which underlies the concept of standard TEI tag sets and is at base denotational. What comes much closer to meeting our model's requirements are the so-called TEI feature structure tags, which are basically a form of user-definable notational convention that can be expanded into as many parameters as one wishes. We therefore decided to adopt the feature-structure concept and put it into practice in terms of a data-base approach. In the next step we developed the prototype of a mark-up tool called TempusMarker. ${ }^{12}$ As the name suggests, TempusMarker assists the mark-up of A- and B-operators in narrative texts. TempusMarker is a stand-alone application, which does not write a full tag into the actual string, but rather inserts a unique placeholder for every defined tag. This short tag ID refers to an external data base file, which contains the fully expanded tag definition.

Actual tagging with TempusMarker is done in a two-step approach. In the pre-processing mode we identify any potential temporal operator by highlighting it in the text and marking it as either an A- or a B-operator, without further expanding its definition. For example, the first 'now' in Poe's novella is simply marked as $<\mathrm{B}>$ now $\langle/ \mathrm{B}>$ to indicate its function as a B-operator. At a later stage of development, a part of this pre-processing routine will be handled automatically by a parser that can identify common temporal expressions. Manual tagging will nevertheless remain a necessity because of metaphorical use of language in literary narratives, which a parser simply cannot resolve. TempusMarker is programmed to store all relevant terms and definitions defined during any manual tagging in an automatically updated and dynamic lexicon file, which will be consulted by the eventual pre-processing parsing routine. Figure 3 presents the TempusMarker interface for the pre-processing routine.

Once pre-processing of the text has been completed the preliminary tags can then be expanded or re-defined. This is supported by TempusMarker's post-processing interface (Figure 4), which enables the user to specify seven parameters, and automatically supplies values for a further five parameters, which are required for the identification of tags and the extension of the text string, which they refer to, as well as for the versioning of single- and multi-user tagging protocols.

The five automatically instantiated parameters are displayed in the bottom row of text boxes (a); they are (from left to right)

(1) Unique Tag-ID (1);

(2) string position of the first and last characters of the mark-up area $(11,13)$;

(3) Version Number, identifying the tagging session per user;

(4) User-ID, identifying the user who is tagging the text.

The (b) row of combo- and text boxes contains the actual semantic parameters that expand the initial tag; these include among others the basic temporal parameters suggested by Pöppel (1978) and Habel and
12 The current TempusMarker prototype is available for download at http:// www.jcmeister.de/html/ tempusmarker1.html. TempusMarker is programmed in VisualBasic 6.0 and runs under Windows 98 and above. 


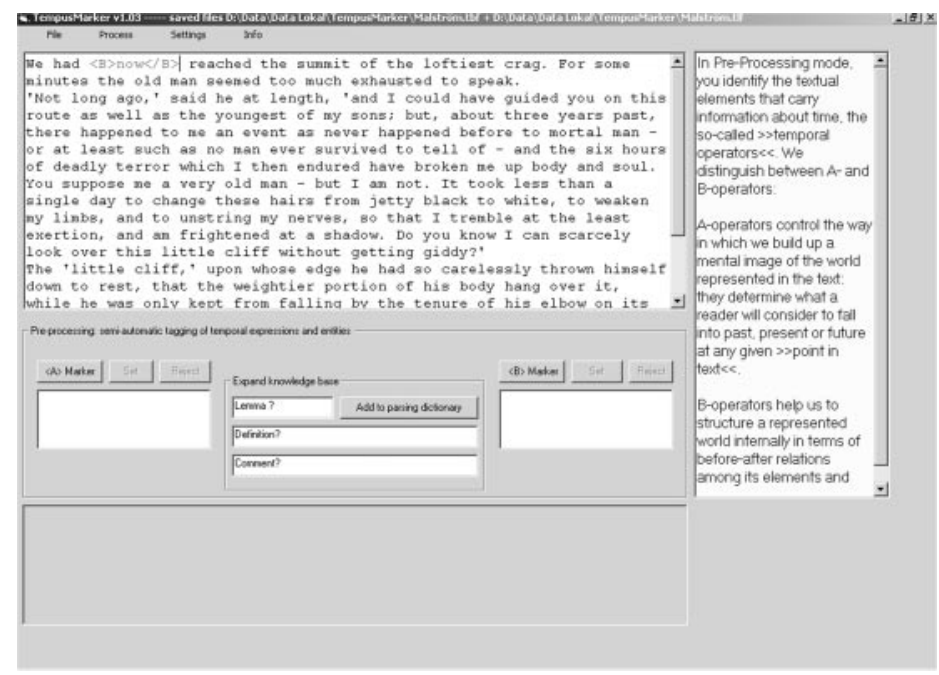

Fig. 3 Pre-processing of electronic text with TempusMarker

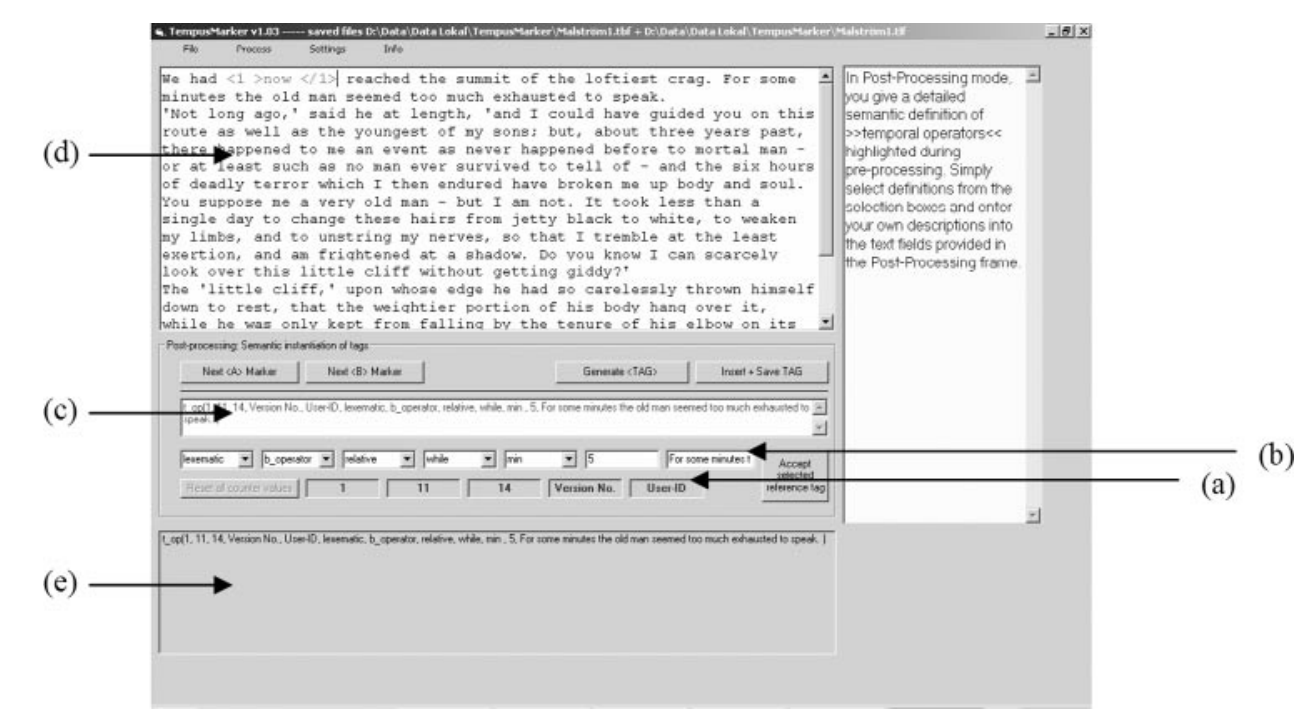

Fig. 4 Post-processing of electronic text with TempusMarker

Schilder (2002). Progressing from one pre-processing A- or B-operator tag to the next with the help of two search buttons, the user can now define the following (from left to right):

(1) the class of textual expression: lexematic (a word), grammatical (a tense or mode), structural (e.g. a paragraph mark), rhetorical (e.g. a repetition, an analepsis etc.);

(2) the type of operator: A- or B-operator. This allows the user to override the pre-processing definition if necessary; 
(3) the mode in which temporal information is conveyed: absolute (e.g. a date) or relative (e.g. a deictic reference like 'at the same time');

(4) the temporal value: 'before, after, while, at, starts, finishes';

(5) the granularity of the expression: 'instant, second, minute, hour, day, week, month, year, generation, epoch, vague';

(6) an optional numerical value;

(7) a potential reference tag to which the current expression is relationally tied. Reference tags can be identified either explicitly or indirectly by highlighting any relevant piece of actual text and confirming the selection with the 'accept'-button. Should this string not yet contain an explicit tag, it will either take on the value of the preceding tag, or that of a tag supplied at a later stage.

When sufficient parameters have been defined we generate the actual tag by clicking the relevant button. The tag will now be shown for inspection in text box (c). If it is found to be correct its tag-ID can then be inserted into the actual text (d) by clicking the 'Insert+Save'-button. The tag-ID will be displayed here while the full tag is automatically stored in an external tag-file, which from now on remains associated with the actual text file.

Finally, the large text box at the bottom of the interface (e) lists all new, as well as the previously defined full tags, which are automatically read in from the associated tag-file. Tag-IDs and fully expanded tags stored in the external file are cross-referenced so that mousing over a Tag-ID will automatically display the full tag. Clicking on a full tag displayed in the bottom text box (e) will result in highlighting the tag-ID within the actual text. There is no limitation to the number of tags per string area marked, or on the complexity or expansion of text highlighted in the tag reference field. Different users may decide to tag the same portion of text using entirely different operators or qualifiers; tags may overlap extensively and so forth. In short, TempusMarker does not insist on unambiguousness of mark-up_-indeed, it is designed to place as little restrictions as possible on the semantic content of temporal mark-up while making sure that the mark-up syntax is consistently applied.

\subsection{Analysis of A- and B-line ordering}

Readers familiar with logical programming languages may have noticed that the expanded TempusMarker tag, which we defined for the first occurrence of 'now' in Poe's A Descent into the Maelstrom takes on the form of a syntactically correct Prolog clause:

t_op $(1,11,13$, Version-No., User-ID, lexematic, b_operator, relative, at, instant, present, 'reached the summit of the loftiest crag. For some minutes the old man')

Similar to Burg et al. (2000) we are using a logic programming approach in the analytical modelling component of our project, the 
so-called TempusParser (currently under development). TempusParser will mainly consist of two sorting algorithms, written in Prolog, which can perform a combinatorial analysis of the tag material stored in the external tag-file and order it, and thereby also the text blocks delimited by these operators, in terms of A- and B-operator information. These algorithms are termed the A- and B-algorithm.

The strength of combinatorial analyses with Prolog (which also plays a fundamental methodological role in my approach toward the combinatorial analysis and exploration of narrated action structures; see Meister (2003)) lies in the fact that one can generate all possible (i.e. rule conformant) permutations, however deeply nested these combinatorial structures may turn out to be. Unlike Burg et al. (2000) our approach does not presuppose an explicit declaration of temporal facts as such (i.e. of the temporal location of represented events) in Prolog syntax. We will leave this task to the machine by instructing it to find out where the content of a text block rendered between two successive temporal operators can be temporally positioned. The semantic 'richness' and extension of these text blocks will be measured in terms of the number of mental images of objects, events and ideas, which are contained within a given block. Again, since we do not want to burden the user with tagging mental images we are also developing a parser that can automatically tag prepositions and nouns (i.e. the lexical elements, which normally represent object or event entities) in our example texts, using either a text-specific thesaurus generated by a concordancer, or-in the case of German language narratives-relying on the capitalisation of nouns and proper names.

Perhaps the most important methodological aspect of TempusParser is that both B-line order and A-line values will be generated 'on the fly' and in relation to a user-defined C-line position on the character string. This resembles the 'continuous model now-slider' approach in Drucker and Nowvieskie (2003), but is conceptually slightly different in that in terms of our model, the now-window is already a dynamic readerly construct, which the Prolog A-algorithm will have to identify, and not a simple user-defined variable. The envisaged combination of the two combinatory Prolog algorithms ultimately aims at a dynamic and explorative model that can visualize what a reader, after processing a specific amount of textual material, and on the basis of a certain interpretation of the temporal operators contained therein, can ideally know about the evolving temporal structure of events, and about the temporal location of object perceptions that take place within the represented world. Moreover, by way of locating and measuring the varying extension of the successive now-windows we also hope to be able to visualize to a certain extent how one knows what one knows about the fictional world's temporality, and how the extent and granularity of this temporal knowledge changes throughout the processing of representational material. Finally, assuming that the mark-up of temporal operators can be objectified to a sufficient extent our model would ultimately also be able to measure and compare 
different narratives in terms of the textual features and components that contribute to the temporality effect, thereby identifying the temporal profile specific to a text or text corpus. The overall architecture of the two interacting programs TempusMarker and TempusParser is outlined in Figure 5.

\subsection{Dynamic visualization of the temporality effect}

The visualization of the dynamically generated views onto the narrated world should ideally combine a graphic representation of the subjective now-window with one for the fictitious objective temporal ordering of events and occurrences in the narrated world. The subjective now-window is defined in terms of the reader's present notion of his or her cognitive position in an A-line continuum of past-present-future, as well as in terms of the extension of that now-window as measured by the number of mental images contained therein. The objective temporal order is expressed in terms of individual events' and occurrences' positioning in the B-line continuum of before-while-after. Accordingly, our suggestion is to interpret the dimensions of McTaggart's model (A-, B- and C-line) as the axes of a $3 \mathrm{D}$ model. We are currently investigating the feasibility of a 3D visualisation, which we have tentatively named the 'rock face model of time' (Figure 6).

In terms of the 'rock face' metaphor the temporality effect - that is, our combined experience of subjective time and objective temporal succession made on the basis of a narrative representation of a fictional world-is a process that resembles the sampling of changing aspects of a mountain range as we walk along that range, eventually deciding to climb it.

Imagine your now-window is located in the horizontal and vertical centre of such a ridge. Let us assume that the bottom layers of the range are the oldest, and that the ridge is located in the future of the mountain range (which is, of course, the opposite of what geomorphology teaches us). This vertical axis visualizes the B-line. Now imagine that you have decided to climb the mountain following a diagonal route from bottom left to top right; this is your subjective A-line. Your subjective now-window is defined in relation to these three axes. From its position and depending on the gradient and the contours as well as on the texture of the rock face in its various places (equivalent to the changing quality and quantity of the mental images in a narrative, and of the temporal operators encountered) you will be able to see a sharp pinnacle here, a deep gully there, then a saddle and so forth. Whenever you move to the right or the left, the vista will change, because you are now on a different vertical section of the rock face; whenever you climb higher or lower, the same will occur because you can see more of the entire mountain range the higher you climb.

Like all analogies the rock face metaphor is of course somewhat forced, and like all visualizations it carries the risk of suggestiveness. We will have to await the outcome of our current experiments 


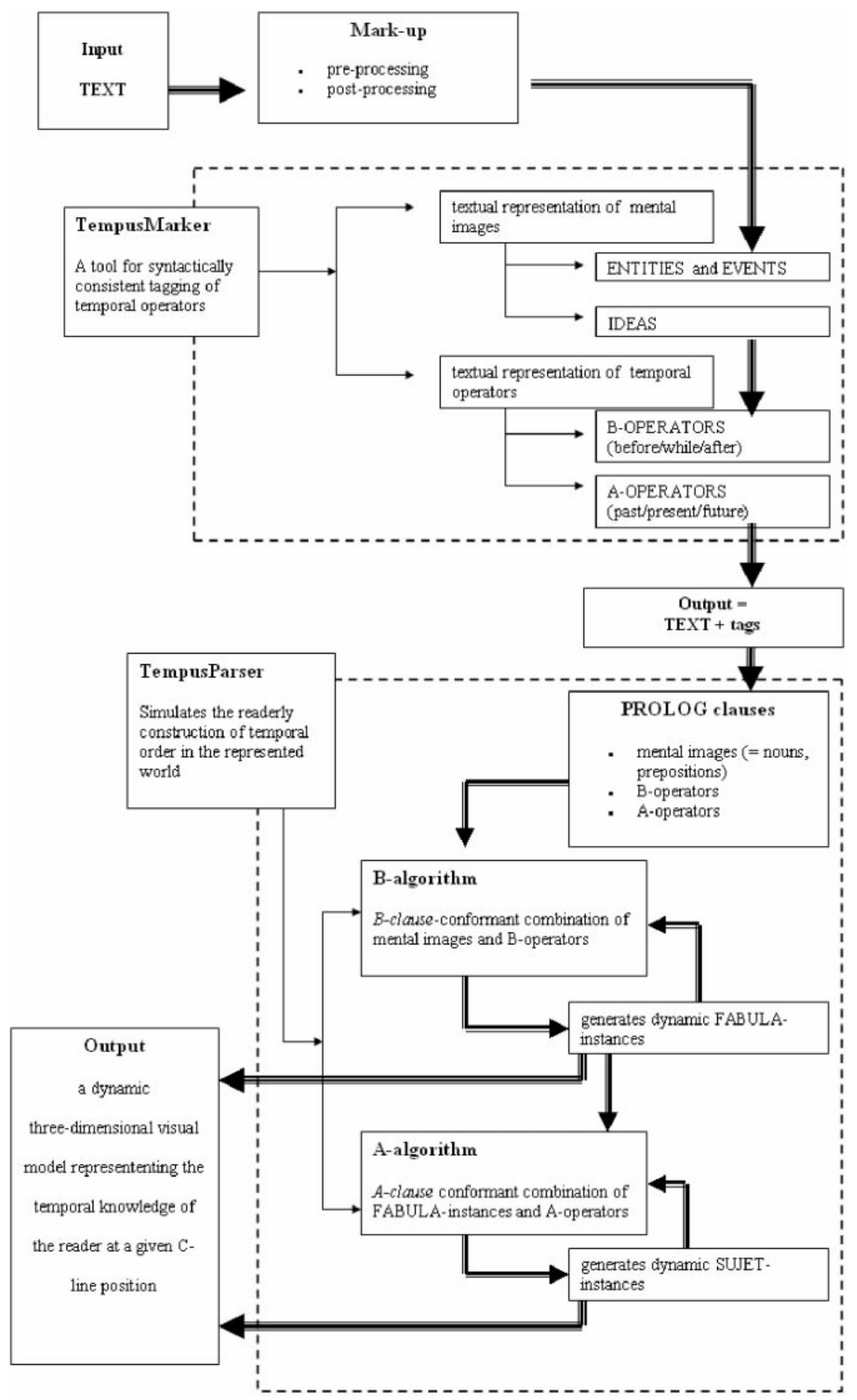

Fig. 5 Overall program architecture of TempusMarker and TempusParser 


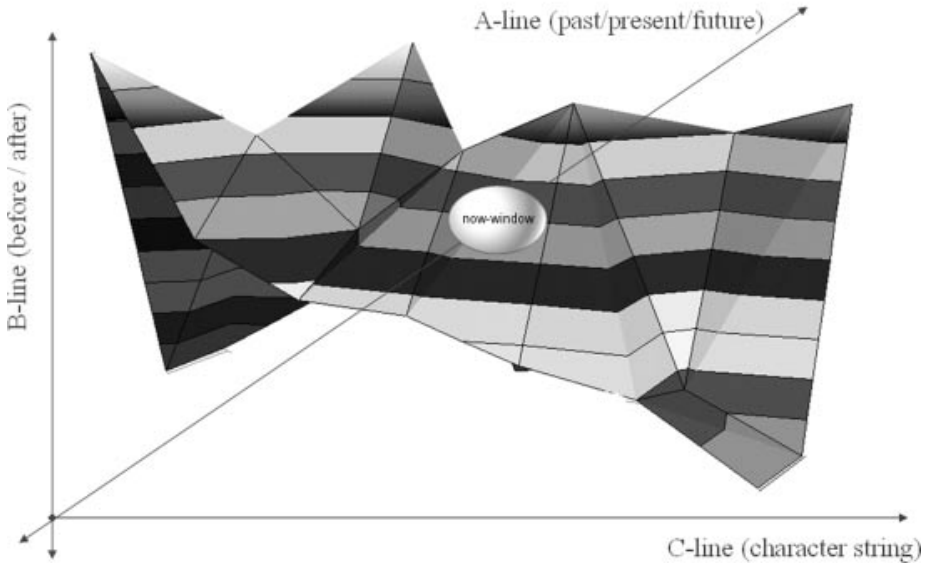

in Flash-visualisation of the rock face model to see whether it can adequately represent the dynamically changing aspects of a narrated world's temporal organisation. These visualisations will have to be generated from the twofold output of TempusParser: from the logic B-line constructs that represent successive instances of the narrated world's state expressed in terms of temporally ordered fictional events and occurrences - the story (fabula) - and from the A-line constructs that represent the successive instances of the discursive process by which these B-line representations themselves were generated, that is, from the dynamic model of the narrative's plot (sujet).

\section{Conclusion}

Our quote from Poe's A Descent into the Maelstrom lacks the conclusive statement of the first paragraph. I believe that it has a certain bearing on our project, and particularly on the rock face model of time: "Do you know I can scarcely look over this little cliff without getting giddy?”

\section{References}

Augustine (1955). Confessions and Enchiridion. Newly translated and edited by Albert C. Outler. Christian Classics Ethereal Library <http://www.ccel.org/ pager.cgi?\&file $=$ a/augustine/confessions/confessions-bod.html\&from $=14.4$ \&up=a/augustine/confessions/confessions.html $>$ (accessed 6 August 2003).

Barthes, R. (1989). The Reality Effect. In The Rustle of Language. Translated by Richard Howard. New York: Hill and Wang, pp. 141-48.

Beer, M. (1988). Temporal Indexicals and the Passage of Time. Philosophical Quarterly, 38: 158-64.

Burg, J., Boyle, A., and Lang, S. (2000). Using Constraint Logic Programming to Analyze the Chronology in 'A Rose for Emily'. Computers and the Humanities, 34: 377-92.
Fig. 6 Rock face model of time 
Drucker, J. and Nowvieskie, B. (2003). The Temporal Modelling Project. $<$ http://jefferson.village.virginia.edu/time/project/index.html $>$ (accessed 6 August 2003).

Dowden, B. (2003). Time. In The Internet Encyclopaedia of Philosophy. $<$ http://www.utm.edu/research/iep/t/time.htm > (accessed 6 August 2003).

Engberg-Pedersen, E. (1999). Space and Time. In Allwood, J. and Gärdenfors, P. (eds), Cognitive Semantics. Meaning and Cognition. Amsterdam: John Benjamins, pp. 131-52.

Genette, G. (1980). Narrative Discourse. Translated by Jane E. Lewin. Foreword by Jonathan Culler. Oxford: Blackwell.

Genette, G. (1988). Narrative Discourse Revisited. Translated by Jane E. Lewin. Ithaca, New York: Cornell UP.

Habel, C. and Schilder, F. (2002). From Temporal Expressions to Temporal Information: Semantic Tagging of News Messages. http:// www.cs.brandeis.edu/ jamesp/arda/time/readings/schilder_habel.pdf (accessed 6 August 2003).

Husserl, E. (1966). Zur Phänomenologie des inneren Zeitbewußtseins (1893-1917). Husserliana, Vol. 10, Den Haag: Martinus Nijhoff.

Husserl, E. (1985). Texte zur Phänomenologie des inneren Zeitbewußtseins, Hamburg: Felix Meiner.

James, W. (1950). The Principles of Psychology, 1890 ed., Vol. 1. New York: Dover.

Lehmann, V. (1992). Grammatische Zeitkonzepte und ihre Erklärung. In Kognitionswissenschaft, Vol. 2, pp. 156-70.

Lehmann, V. and Rauchenecker, E. (1995). Temporale Implikationen Nichttemporaler Kategorien. In Jachnow, H. and Wingender, M. (eds), Temporalität und Tempus. Studien zu allgemeinen un d slawistischen Fragen. Unter Mitarbeit von Karin Tafel. Wiesbaden: Harrassowitz.

McTaggart, J. (1908). The Unreality of Time. In Mind, Vol. 17, pp. 457-74.

Meister, J.C. (2003). Computing Action. A Narratological Approach. Berlin, New York: De Gruyter.

Müller, G. (1948). Erzählzeit und erzählte Zeit. In Festschrift für Paul Kluckhohn und Hermann Schneider. Tübingen: Mohr, pp. 195-212.

Pöppel, E. (1978). Time Perception. In Held, R. et al. (eds), Perception. Berlin: Springer, pp. 713-729 (Handbook of Sensory Physiology 8).

Propp, V. (1984). Morphology of the Folktale. Second Edition, Revised and Edited with a Preface by Louis A. Wagner. With a New Introduction by Alan Dundes (American Folklore Society. Bibliographical and Special Series 9). Austin, TX: University of Texas Press.

Protevi, J. (1999). "Inventio" and the Unsurpassable Metaphor: Ricoeur's Treatment of Augustine's Time Meditation. Philosophy Today, 43: 86-94.

Ricoeur, P. (1984-1988). Time and Narrative. 3 vols. Vol. 1 (1984) and Vol. 2 (1986) translated by Kathleen McLaughlin and David Pellauer; Vol. 3 (1984) translated by Kathleen Blamey and David Pellauer. Chicago and London: University of Chicago Press.

Robinson, H. (ed.). (1987). The B-Deduction. Vol. XXV, Supplement. The Southern Journal of Philosophy. Memphis: Memphis State University. 
Ryan, M-L. (1991). Possible Worlds, Artificial Intelligence and Narrative Theory. Bloomington: Indiana University Press.

Sandbothe (1988). Die Verzeitlichung der Zeit. Grundtendenzen der modernen Zeitdebatte in Philosophie und Wissenschaft. Darmstadt: Wissenschaftliche Buchgesellschaft.

Sperberg-McQueen, C.M. and Burnard, L. (eds). (2002). TEI P4: Guidelines for Electronic Text Encoding and Interchange. Text Encoding Initiative Consortium. XML Version: Oxford, Providence, Charlottesville, Bergen. Chapter 20. 4: 'Dates and Time'. Avialable at http://www.tei-c.org/P4X/ ND.html\#NDDATE (accessed 4 August 2003).

Wittman, M. and Pöppel, E. (1999). Neurobiologie des Lesens. In Franzmann, Bodo et al. (eds), Handbuch Lesen. Im Auftrag der Stiftung Lesen und der Deutschen Literaturkonferenz. München: K. G. Saur, pp. 224-39. 